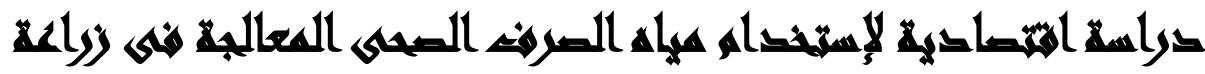

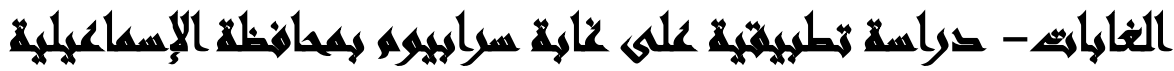

[10]

\author{
أحمد فؤاد مندور(')- نظمى عبد الحميد عبد الغتى(؟)- محمود أحمد حويحى(־)

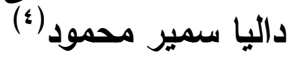

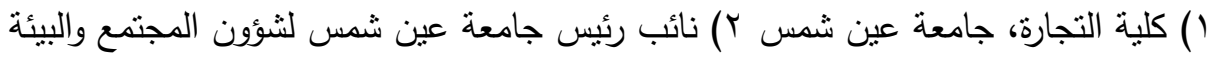

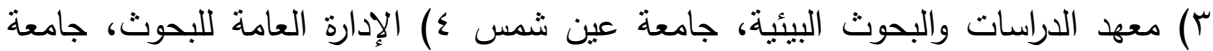

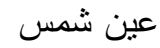

\section{المستخلئس}

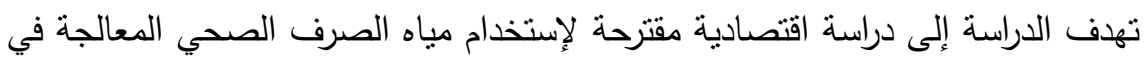

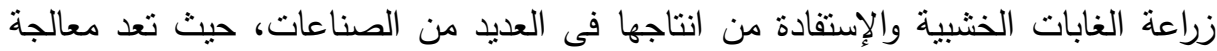

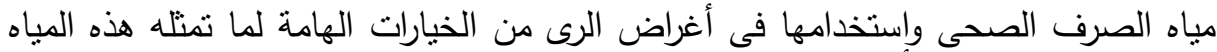

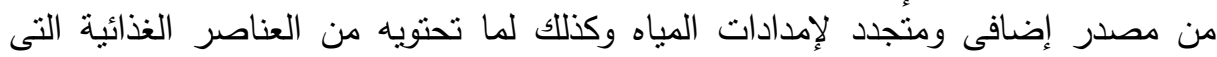

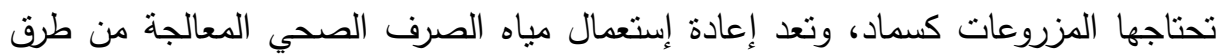

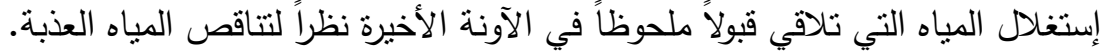

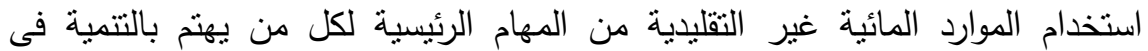

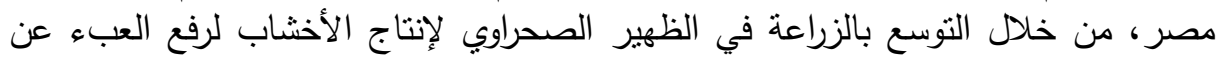

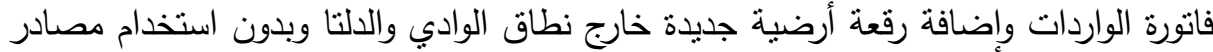
مياه تقليدية للري.

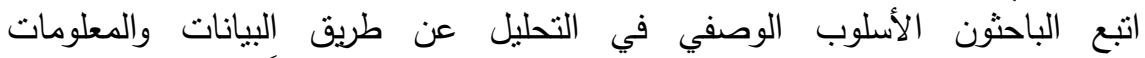

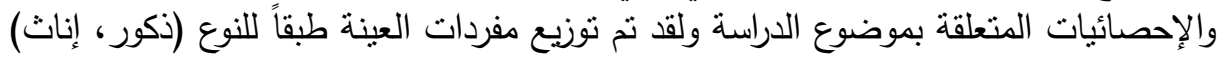

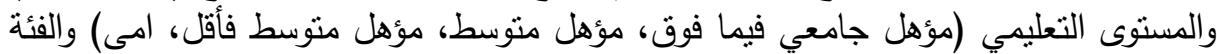

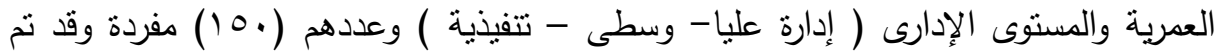

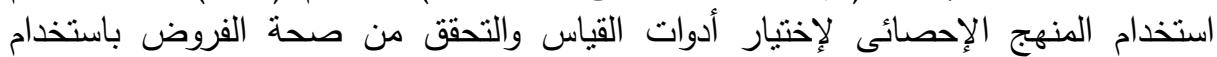

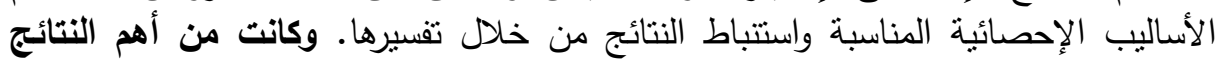
التي توصلت إليها هذه الدراسة:

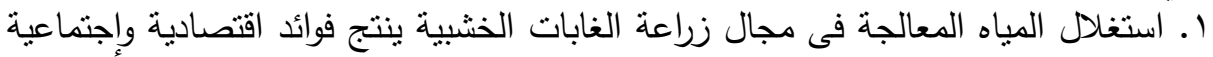
وبيئية تسهم فى التتمية المستدامة لمناطق صحرال فراوية هامثية وغير مستغلة.

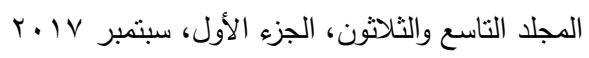


r. يمكن تحسين إدارة مياه الصرف الصحي المعالجة من خلال تحسين السياسات المؤسسية

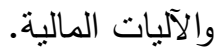

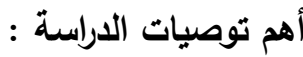

ا ـ تشجيع الاستثمار في مجال زراعة غابات الأشجار الخشبية وعرض النماذج المقترحة على

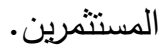
r. ضرورة التوسع في إقامة محطات تتقية ومعالجة مياه الصرف الصحي لإعادة إستخدامها

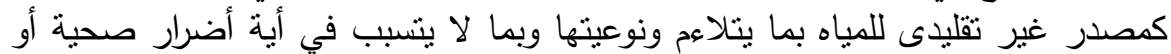
بيئية حتى لا تتأثز صحة الإنسان ومن ثم إنتاجيته.

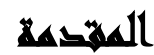

إن الحاجة الماسة إلى الغذاء والماء نتيجة لنمو السكان المتزايد فى مصر تستوجب التوسع فى الزراعة وكذلك التوسع فى توفير إمدادات المياه، لذا أصبحت الأراضي الزراعية

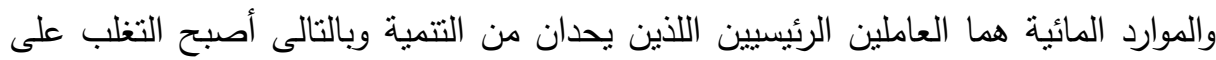

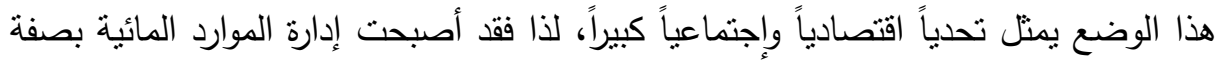

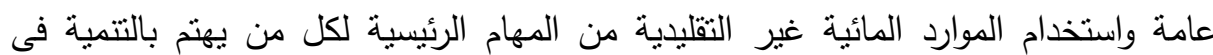
مصر ، وتعد معالجة مياه الصرف الصحى واستخدامها فى أغراض الرى من الخيارات الهامة لما تمثلك هذه المياه من مصدر إضافى ومتجدد لإمدادات المياه وكذلك لما تحتويه من

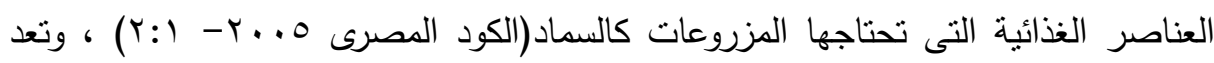
إعادة استخدام مياه الصرف الصحي المعالجة من طرق إستغلال المياه التي تلاقي قبولاً

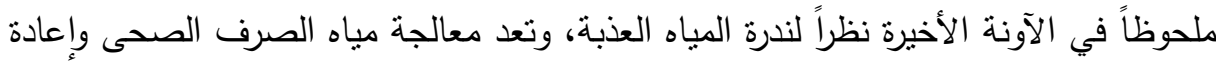
استعمالها هى أحد الخيارات العلمية في سبيل توفير مصادر جديدة للادئ للمياه نظراً لمحدودية الموارد المائية وتلبية الحاجة المتزايدة للمباه في مصر وكذلك لتحقيق الثروط الخاصة بالتخلص من هذه النوعية من المياه بالثكل الذى يساعد على حماية البيئة والصحة العامة، لهئه

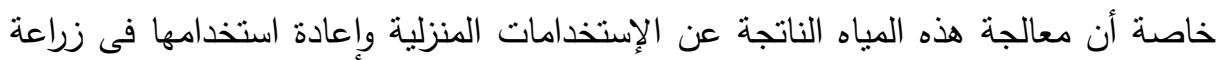

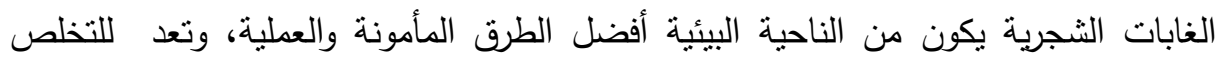
من (Ali Shehata 2013-324:353) 
حيث تهتم الدولة بالمحافظة على بيئة نظيفة وتعطى أولوية قصوى لمواجهة مختلف

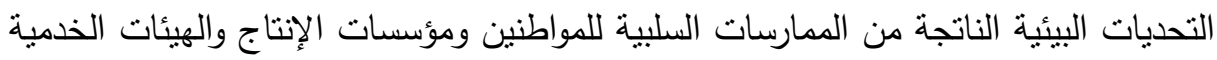
مما يلوث البيئة وتمتل خطر على صحة الإنسان واستنزاف للثروات الطبيعية وتأنى المياه من المصادر الطبيعية التي يجب الحفاظ عليها من التلوث بجانب الإستفادة الآمنة من مياه

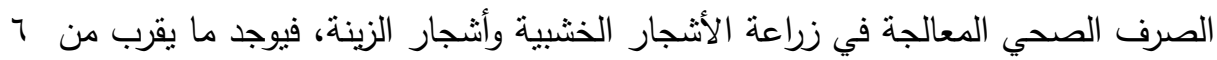

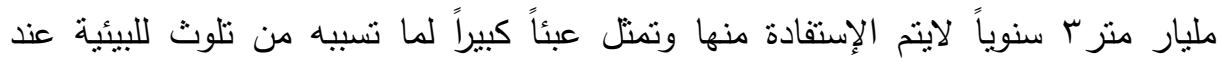

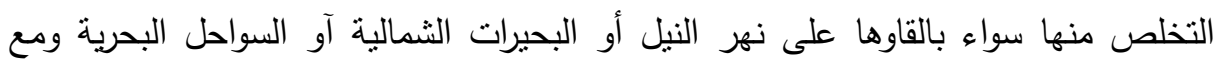

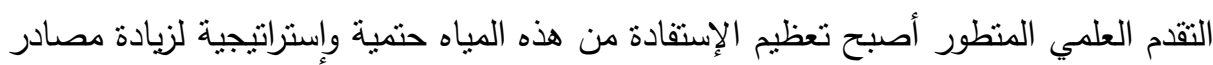

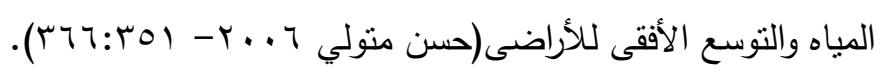

\section{مش2/}

الزيادة المستمرة فى عدد السكان والتقدم الصناعى فى جمهورية مصر العربية، والزيادة المستمرة فى معدلات استهلاك المياه وارتفاع مستوى المعيشة والرفاهية وزيادة استخدام المنظفات والمواد الكيميائية المختلفة والتى يصرف أغلبها مـع مخلفات الصرف الصحى الصى مما يجعل من المخلفات السـائلة مشكلة كبيرة، ويؤدى عدم الكفاءة فى إدارة مشاريع معالجة هذه المخلفات إلى تفاقم آثارها عاماً بعد عام فى ظهور العديد من المشكلات سواء نقل الأمراض مثل الكوليرا والتيفود والحميات وتلويث المياه الجوفية والتربـة الزارعيـة بالإضـافة

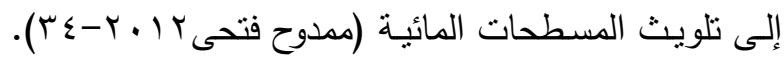

نظراً لأن البيئة المائية المصرية عبارة عن حوض مغلق تدخل المياه فيه من مصدر

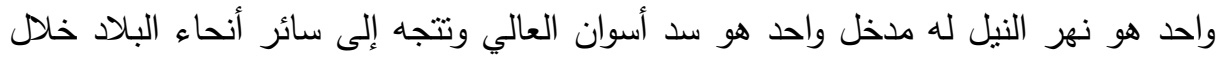

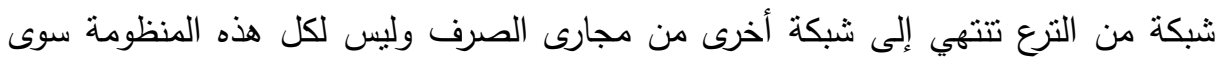

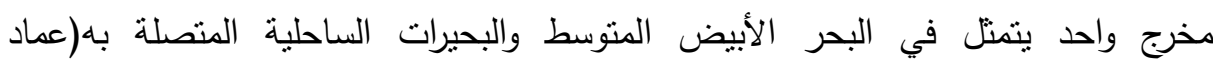

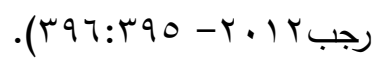

مما يهدد البيئية والتتوع الحيوي بها بسبب الآثار السلبية المتعددة على الإنسان والثروة السـكية والإخـال الخطير بـالتوازن البئُى للكائنـات الحيـة.

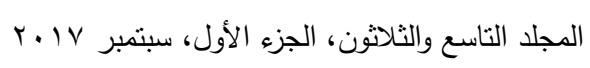


تم الاستعانة بعدة دراسات سابقة عربية وأجنبية ساهمت بشكل كبير وأساسي في اختيار وتحديد مشكلة الاراسة، وفيما يلى عرض لبعض من هذه الدراسات:

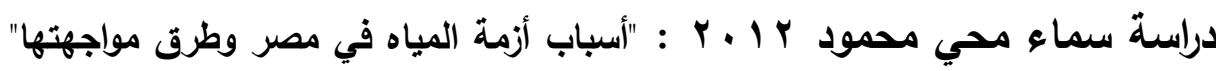

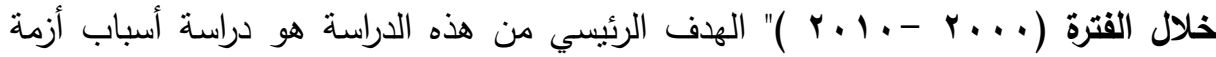
المياه فى جمهورية مصر العربية والموارد المائية المتاحة فى مصر سواء موارد تقليدية طبيعية وموارد غير تقليدية وكذلك دراسة حجم الطلب على تللك المياه والنسب المهدرة منها سواء بالطرق المباشرة أو غير المباشرة وطرق تحسين إدارة المياه على المستوى الزراعي وعلى دورلى مستوى مياه الثرب وترشيد إستخدام الموارد المائية عن طريق مشروعات تحسين كفاءة الري

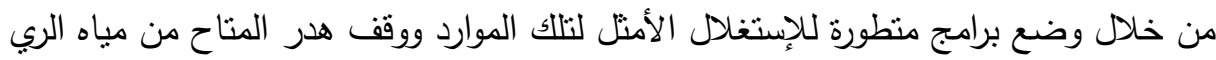

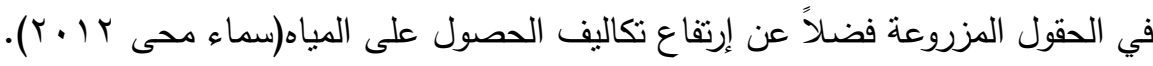

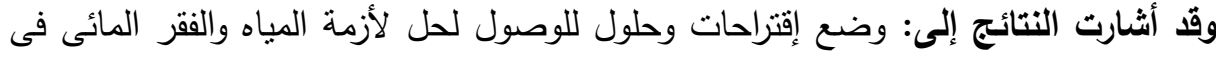
مصر من خلال ترشيد الإستهلاك ووضع حلول وطرق لمشروعات تحسين كفاءة الري والوسائل والآليات التى تساعد على حل تلاك الأزمة والثح المائى . تعقيب: وتتشير هذه الدراسة إلى عرض مشكلة أزمة المياه والطرق والآليات التى يمكن إستخدامها لحل تلكك الأزمة من خلال الإستغلال الأمتل للموارد المائية التقليدية والغير تقليدية. دراسة محمد حافظ الماحى وأخرون(Y 1 · ): "التوجيه الاثتصادي لاستخدام مياه الصرف الصحي المعالج في تنمية الظهير الصحراوي" تتلخص فكرة البحث في استغلال مياه الصرف الصحي المعالج في عمل حزام أخضر في الظهير الصحر اوي حول المدن

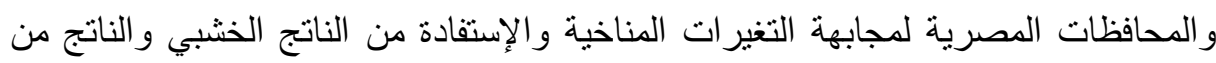
الزيوت المستخدمة كمحنات حيوية لوقود المحركات و الطائر ات وبذللك يمكن إضافة رقعة التهن أرضية جديدة باستخدام مياه الصرف الصحى المعالج. 


\section{وقد أثارت النتائج إلىى:}

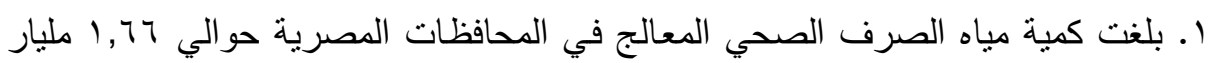
مترب من محطات الصرف الصحى البالغ عددها ابا محطة موزعة على جميع المحافظات.

r. قدرت مساحة الظهير الصحر اوي للمحافظات المصرية حوالي بr،r مليون فدان وبعد

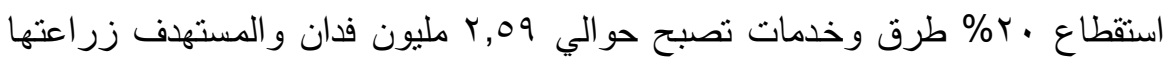

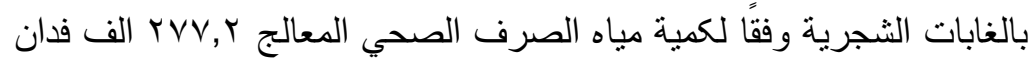
r. بلغت تكلفة معالجة مياه الصرف مياه الصرف الصحي المعالج في المحافظات بات باه المصرية حوالى بr مليار جنيه علاوة على التكاليف الإنثائية للغابات والتي إذا نفاه

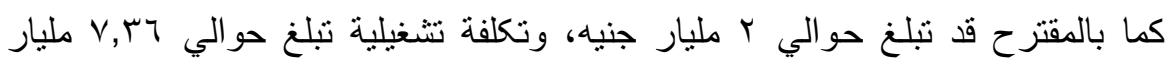

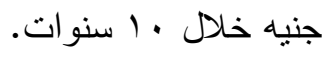

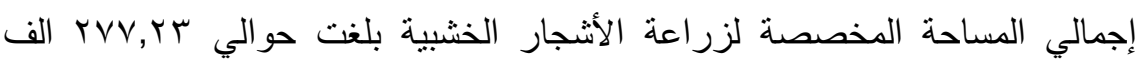

تعقيب: وتتير هذه الدراسة إلى أن تحويل مياه الصرف المعالج لأطر اف المدن والمحافظات إلى الظهير الصحر اوي كمصدر لري الغابات الثجرية والتي يمكن استغلالها كحزام أخضر إنسر حول المدن كمنتز هات أوبيعها للمستثمرين كنماذج مزرعية حديثة.

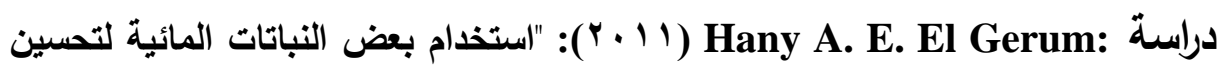
نوعية النفايات السائلة ": تم إجراء دراسة تجريبية على مخرج محطة الإسماعيلية لمعالجة مياه الصرف الصحي فى مصر لتحديد كفاءة بعض النباتات المائية وتحسين نوعية النفايات السائلة،وقد تمت دراسة كفاءتها في تطوير مياه الصرف الصحي في البحيرة على مدى سنة واحدة .وقد تم ذلك من خلال دراسة كفاءة ثلاث نباتات مائية بشكل فردي وفي سلسلة .

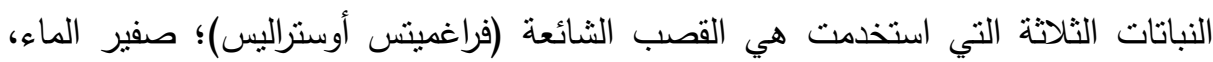
(إيثورنيا كراسييس) وعصير الطحلب ليمنا غييا. 
وقد أثشارت النتائج إلى: محتوى المغذيات والمعادن الثقبلة قد انخفض بشكل ملحوظ من خلال استخدام هذه النباتات بشكل فردي وفي سلسلة، كما نم تخفيض أنواع الطحالب وأعدادها في مياه الصرف الصحي للبحيرات بشكل ملحوظ بسبب المنافسة في امتصاص المغذيات مع هذه النباتات العليا، وتتمتع النفايات السائلة الناتجة بعد الدراسة التجريبية بنوعية ممتازة ويمكن لئن استخدامها بأمان في الزراعة أو للتخلص منها في بيئة مائية.

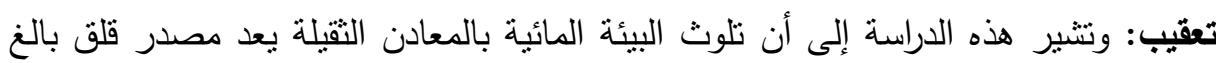

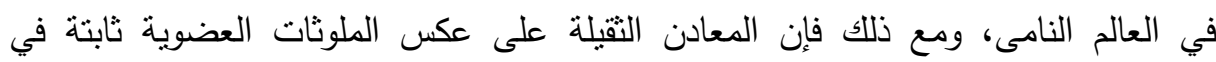
الطبيعة وتميل إلى التراكم في مختلف مكونات البيئة.

\section{أسئلا التراسلا}

ومن هنا يمكن بلورة مشكلة الدراسة في الإجابة عن التساؤلات التالية:

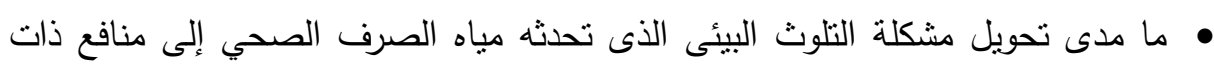

قيمة اقتصادية وبيئية بمعالجتها وإعادة استخدامها كأحد المصادر الغير تقليدية للمياه ؟

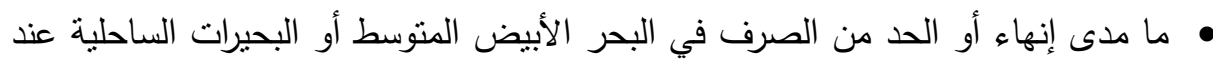
إستغلال هذه الكمية الكبيرة من المياه المعالجة في بعض الزفر الزراعات المسموح بها كزراعة

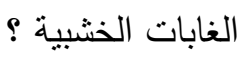

• ما مدى مساهمة معالجة مياه الصرف الصحي وإعادة الإستخدام الأمن لها في تحسين البيئة فى جمهورية مصر العربية، ومنع الضرر بصحة الإنسان والكائنات الحية الأخرى

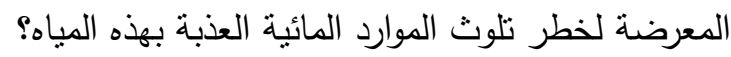

\section{أهساهي الترلهة}

ا. الإستفادة من مياه الصرف الصحي بمعالجتها وتحويلها إلى قيمة اقتصادية بدلاً من صرفها على نهر النيل أو البحار مما يؤدي إلى التلوث البكتربيولوجي والفيروسي 
والكيماوي للمياه بالإضافة إلى تدهور النظم الأيكولوجية الخاصة بالثروة السمكية النهرية والبحرية.

r. المساهمة فى تعظيم العائد الصحى على الأفراد نتيجة القضاء على مصادر نوالد الحشرات

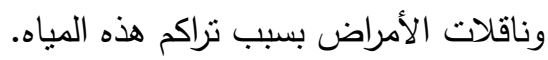
r. تتكيل مناطق جذب وتتمية للسكان اللذين يمكن تواجدهم فى منل هذة المناطق.

\section{هزوضر التراسما}

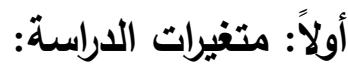
ا ـ استخدام مياه الصرف الصحى المعالجة فى الزراعة وخاصة الغابات

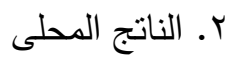
r. عجز الموارد المائية

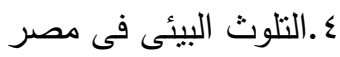

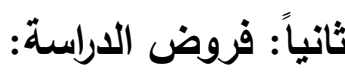

• لا توجد علاقة معنوية بين استخدام مياه الصرف الصحي المعالجة فى زراعة الغابات وزيادة الناتج المحلى الإجمالي.

• لا توجد علاقة معنوية بين استخدام مياه الصرف الصحي المعالجة فى زراعة الغابات

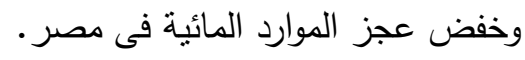

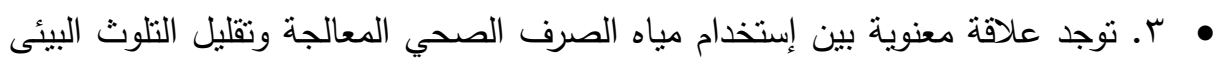
فى مصر.

\section{هصور الدواسمة}

الحدود المكانية: وتتمثل فى المجال الجغرافى وهوغابة سرابيوم بمحافظة الإسماعلية

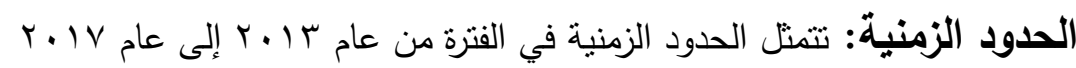




\section{منهمجية التوراسة}

اتبع الباحثون الأسلوب الوصفي في التحليل عن طريق جمع البيانات والمعلومات والإحصائيات المتعلقة بموضوع الدراسة سواء من الكتب أو الثقارير والدوريات والمؤتمرات العلمية وتبويبها على هيئة جداول ومؤشرات ورسوم بيانية ومن ثم وصفها وتحليلها واستخلاص المعلومات منها كما استخدموا المنهج الاحصائى لإختيار أدوات القياس والتحقق من صحة الفروض باستخدام الأساليب الإحصائية واستتباط النتائج وتفسيرها.

\section{أهمية التوراسة}

زيادة كفاءة استخدام مياه الصرف الصحي بتدويرها واعادة استخدامها أفضل من الناحية

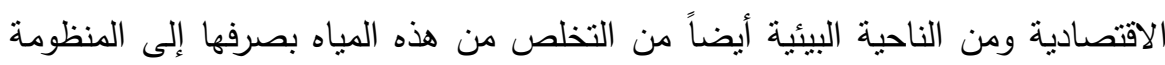
المائية. • استغلال المياه المعالجة في مجال زراعة الغابات وما يمكن إن ينتج عن ذلك من فؤائد اقتصادية واجتماعية وبيئية نسهم فى التتمية المستدامة لمناطق صحراوية هامثية وغير لهني مستغلة لتحويلها الى مساحات منتجة اقتصادياً وتسهم أيضاً في تحسين البيئة في جمهورية

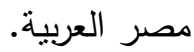

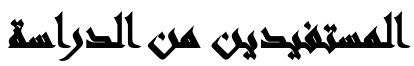

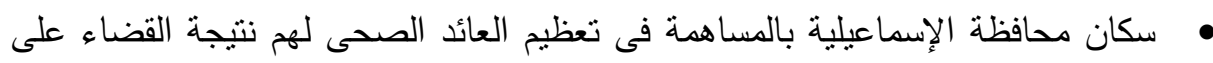

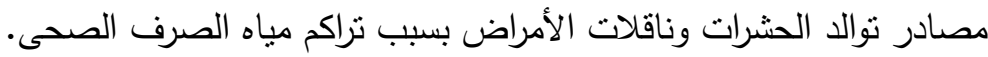
الثباب بتوفير فرص عمل جديدة لهم من خلال الصناعات القائمة على منتجات غابة لتراه

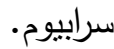
• • حماية مصادر المياه والتربة بمحافظة الإسماعيلية من التلوث. • تحسين ميزان الددفوعات بمصر من خلال توفير جزء من الأخشاب المنتجة محلياً بدلاً من الإستيراد الكامل من الخارج. 


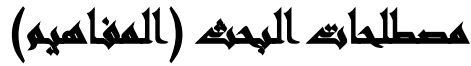

• مياه الصرف الصحى (الكود المصرىه .. ب-1 (17 1): المباه الناتجة عن الإستخدامات

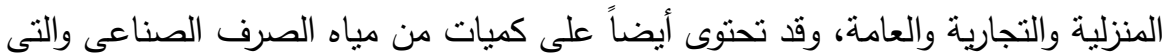
قد تكون قد خضعت لمعالجة تمييدية تفى بمتطلبات ربطها بشبكة الصرف.

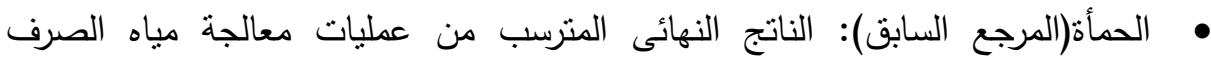

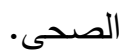

• مياه الصرف الصحى المعالجة(المرجع السابق): مياه صرف صحى خضعت لمعالجة ملائمة فى محطة متخصصة لهذا الغرض بحيث تكون جودة المياه الناتجة ملائمة للإستخدام فى أغراض نافعة.

\section{التراسايت الساوية}

ا - دراسة أحمد السرورى 10 ب ب، مياه الصرف المعالجة الأهمية والمنافع

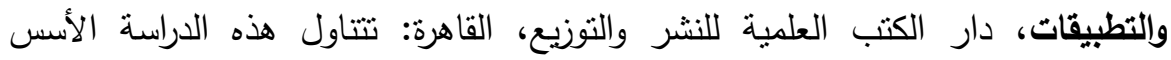
الضرورية والإعتبارات الأساسية الخاصة بموضوع إدارة مياه الصرف الصحى( المياه العادمة ) وإعادة استخدامها من حيث الأهمية والمنافع والتطبيقات. توصلت الدراسة إلى النتائج التالية: • أهمية إستخدام مياه الصرف الصحى المعالجة فى المجالات المختلفة لتدارك النقص فى في الموارد المائية المتاحة وفى زيادة كمية المحصول وتوفير الأسمدة الكيميائية. إستخدام مياه الصرف الصحى المعالجة يساعد فى تخفيف التلوث البيئى الناتج من الصرف الصحى وذلك عند إتباع الطرق الصحيحة فى المعالجة والإستخدام.

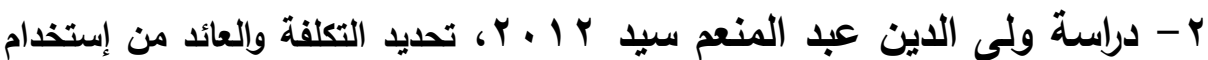
مياه الصرف الصحى المعالج حيوياً (دراسة ميدانية بمدينة شرم الثيخ)، ماجستير معهد الدراسات والبحوث 
البيئية، جامعة عين شمس: تنتاول هذه الدراسة تحليل التكلفة والعائد من إستخدام مياه الصرف الصحى المعالج لمواجهة مشكلة قلة مصادر المياه وإرتفاع تكلفة الحصول عليها هنها والتخلص الآمن من مياه الصرف الصحى الناتجة عن الأنشطة السياحية بمدينة شرم الثيخ

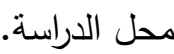
توصلت الدراسة إلى النتائج التالية: • إستخدام المياه المعالجة فى الزراعات المسموح بها كزراعة الغابات الخشبية ينهى أو يحد من الصرف في البحر أو البحيرات الساحلية المتصلة به. • إعادة الإستخدام الآمن للكميات الهائلة من مياه الصرف الصحي بعد معالجتها فى مجال

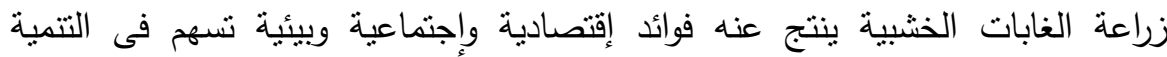
المستدامة، وأيضاً يسهم فى منع الضرر بصحة الإنسان والكائنات الحية الأخرى.

Kfir Narkis, Shmuel Assouline: Effect of Long-Term Irrigation with Treated Wastewater on the Root Zone Environment,Vol 12 Issue 2, May 2013.

"تأثير الري طويل الأجل بمياه الصرف الصحي المعالجة في منطقة جذر الثجرة": تتتاول هذه الدراسة تقييم تأثير 17 سنة من الري بمياه الصرف الصحي الصي المعالجة على الشروط التي وضعت في منطقة الجذر من شجرة الأفوكادو المزروعة فى التربة الطينية ومقارنتها بالرى

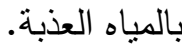
وتوصلت الدراسة إلى النتائج التالية: استخدام الري بمياه الصرف الصحي المعالجة أدى إلى ارتفاع الملوحة فى التربة، وانخفاض التوصيل الهيدروليكى.

Roig, J., Martí, E., Nadal, M. et al: Long-term amendment of Spanish soils with sewage sludge: Effects on soil, 20 September 2012, vol:168, Issue 298, pp:41-48.

"أثار حمأة مياه الصرف الصحى على المدى الطويل على التربة"قامت هذه الدراسة بإجراء

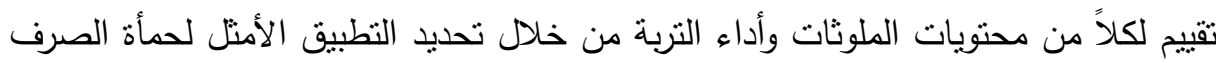
الصحي لمدة 7 اعام على حقول القمح في بامبلونا في شمال اسبانيا، واستخدمت ثمانية 
معالجات مختلفة ومتفاوتة في كمية الحمأة، وحللت مجموعة من خصائص التربة، فضلاً عن دراسة السمية المحتملة للنباتات وأثارها على نمو النبات. توصلت الدراسة إلى النتائج التالية: • أدت حمأة المجاري إلى تغيير فى خواص التربة حيث كانت هنالك زيادة في حموضة التربة والمواد العضوية في التربة، ومستويات الكربون العضوي، ومستويات النيتروجين في التربة ونشاط الكائنات المجهرية في التربة. تطبيق الحمأة بشكل متكرر أكثر من مرتين في السنة يؤدى إلى الإضرار بالتربة.

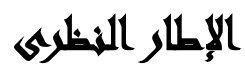

أهمية معالجة مياه الصرف الصحى:(وزارة الموارد المائية ا.ـ-9ه9) أولاً: تستخدم مباه الصرف الصحي بعد القيام بعملية التكرير والمعالجة في الاستخدام الزراعي بحيث يعتمد عليها في ري المزروعات.

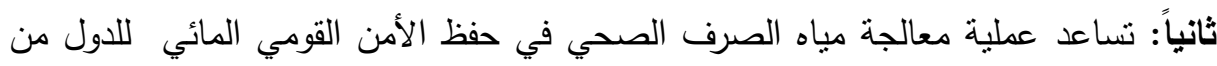
خلال تكرير المياه وإعادة استخدامها وتحقيق الإكتفاء الذاتى لديها من مصادر المياه التى

ولذلك فإن تطبيقات استخدام هذه النوعية من المياه يتطلب:

• تجنب أى أضرار بكتيرية وتأثيرها على المحاصيل والثمار التى ينم إنتاجها وتداولها. • إختيار نوعية مناسبة من المحاصيل تتفق وهذة المحددات.

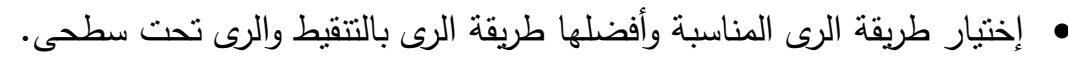
اشتراطات السلامة الصحية للقائمين على استخدام تلك النوعية من المياه في الزراعة:

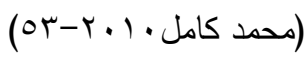
ه استخدام قفازات واحذية مناسبة ذات رقبة عالية لمنع التلامس بالمياه. • التطعيم ضد الكوليرا والتنفود والإلتهاب الكبدى الوبائى. • الكثف الطبى الدورى مرة كل سنة على الأقل. • • نوفير مكان نظيف بة مياه نقية لفترات الراحة والأكل أثثاء العمل.

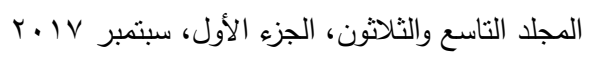




\section{ما هى مراحل معالجة مياه الصرف الصحى(نبيل فتحى 1 ـــ-7ه)} المرحلة الأولى: المعالجة الطبيعية والتى تشمل التخلص من المخلفات والثوائب العالقة بمختلف أنواعها بالإضافة إلى التخلص من الرمال العالقة. المرحلة الثنائية: وتشمل المعالجة البيولوجية وفيها يتم إذابة الأكسجين الحيوى فى المياه لإنعاش البكتيريا الهوائية وتشمل أحواض الترسيب التى يتم من خلالها فصل الماء الصافى لته

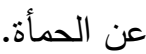
المرحلة الثلاثية: وتتمل فلتزة المياه المعالجة ثنائياً بواسطة المرشحات الرملية مع إضافة غاز

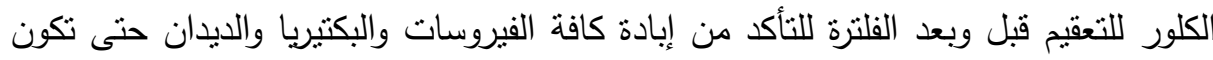

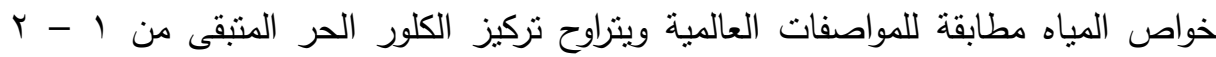

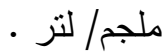

الأهمية الاقتصادية لتعظيم الإستفادة من استخدام مياه الصرف الصحى المعالجة فى زراعة

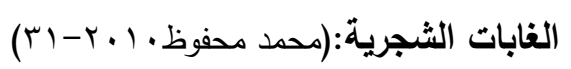
• زيادة العائد الاقتصادى والدخل القومى نتيجة إستغلال الأثجار الخشبية فى الصناعات الخشبية(الأثاث) والتصنيع الزراعى من الزيوت وألياف أو أعلاف حيوانية. إنثاء مصنع لإنتاج الحبال من أشجار السيسال. • إحلال الأخشاب المنتجة محلياً محل الأخشاب المستوردة بما يحسن ميزان المدفوعات وخفض التضخم.

\section{إجيراءايه السواسمة}

مجتمع وعينة الدراسة: يتمثل مجتمع الدراسة في جميع العاملين الموجودين وقت إجراء الإستقصاء فى مارس / V V ا ب بمختلف المستويات التعليمة ( مؤهل جامعي فما فوق - مؤهل متوسط فما فوق - مؤهل متوسط فأقل - أمى ) فى الأماكن الثالية: • محطة معالجة مياه الصرف الصحي بسرابيوم بمحافظة الإسماعلية.

$$
\text { غابة سرابيوم بمحافظة الإسماعلية. }
$$


شركة المياه والصرف الصحى بمحافظات القناة ومقرها محافظة الإسماعيلية. عينة الدراسة: نم توزيع ( (1) استمارة على مفردات مجتمع الدراسة وقد بلغ عدد الاستمارات

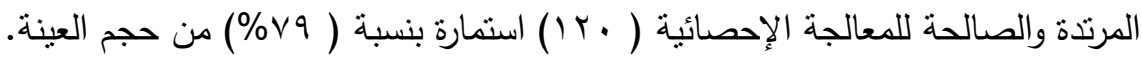

\section{أسواهث الصواسمة}

اتبع الباحثون الأسلوب الوصفي في التحليل عن طريق جمع البيانات والمعلومات والإحصائيات المتعلقة بموضوع الدراسة سواء من الكتب أو الثقارير والدوريات والمؤتمرات العلمية وشبكة المعلومات الدولية وتبويبها على هيئة جداول ومؤشرات ورسوم بيانية ومن ثم تثراء وصفها وتحليلها واستخلاص المعلومات منها لجمع ما يخص طبيعة البحث من احصاءات ومنشورات.

كما استخدم المنهج الاحصائى لإختيار أدوات القياس والتحقق من صحة الفروض بإستخدام الأساليب الإحصائية واستتباط النتائج من خلال تفسيرها. الدراسة العملية ومصادر البيانات: تنشمل المرحلة الثانية للاراسة البحثية الدراسة الميدانية البانية وتخضع لهجموعة من المحددات وهى توجيه استمارة استبيان قد نم اختيارها فى نطاق محدد ثم إجراء مقابلات شخصية مع المبحوثين وهم: المسؤلين والباحثين والفنيين والعاملين بمحطة معالجة مياه الصرف الصحي بسرابيوم بمحافظة الإسماعلية.

$$
\text { العاملين بغابة سرابيوم من ( مهندسين زراعيين - مزارعين - فنيين - عمال). }
$$

السادة المسؤلين والعاملين بالثركة القابضة لمياه الثرب والصرف الصنئ الصحى بمحافظات القناة بمحافظة الإسماعيلية. احتوت استمارة الاستبيان على واحد وثلاثون سؤال نم تقسيمهم فى ثلاث مجموعات

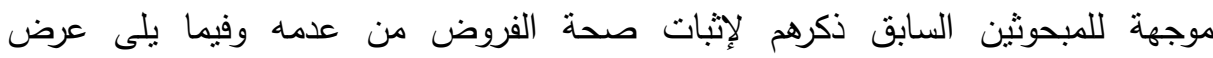
لمجموعات اسئلة استمارة الاستنيان: • هل توجد علاقة بين استخدامات مياه الصرف الصحي المعالجة في الزراعة والناتج المحلى الإجمالي (بال سؤال). 
• • هل توجد علاقة بين استخدامات مياه الصرف الصحي المعالجة والتلوث البيئي (

• هل توجد علاقة بين استخدامات مياه الصرف الصحي المعالجة وانتشار الأوبئة والأمراض

.

صدق الاستبيان: وقد تم عرض الاستبيان على مجموعة من المحكمين فأفادو بمناسبتها، وتم

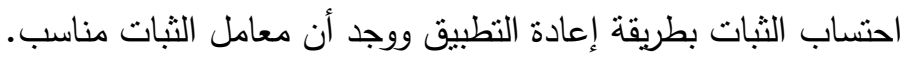

\section{ingis}

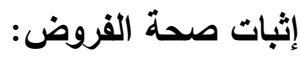

جدول رقم(1): التكرارات النسبية \% والإحصاء الوصفي للفرض الاول

\begin{tabular}{|c|c|c|c|}
\hline ترأهميبة & معياري & مرجح & أسئلة:الاراسة \\
\hline 1 & .70 & $\varepsilon, r_{q}$ & يستهلاك القطاع الزراعي ما يقرب من · ج\% من إجمالى المياه المستككة سنوياً \\
\hline$r$ & $r, \mathrm{VV}$ & $\varepsilon, 10$ & مياه الصرف الصناصر الصحي المعالجة قد تزيد من الإنتاج لإحتوائها على بعض \\
\hline r & $\cdot, \wedge$. & $\varepsilon, \cdot \varepsilon$ & استخدام مياه الصرف الصحي المعالجة يحتاج إلى مصادر دائمة للتمويل \\
\hline M & $1, Y 7$ & r, १V & نفقات معالجة مياه الصرف الصحي تشمل نفقات حماية المزارعين من الأمراض \\
\hline 11 & $1, \cdot 7$ & r, ז & سرابيوم يساهدم في زبادة الصرف الصحى المعالجة فيى زراعة الأشجار الخشبية بغابة \\
\hline$\wedge$ & $\cdot, 9 \wedge$ & 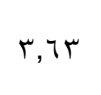 & زيادة العائد المالي مباه الصرف الصحى المعالجة في زراعة الأشجار الخشبية يؤدى الى \\
\hline ir & 1,17 & T, Th & يتم الإلتزام بتنفيذ اللوائح والقوانين عند استخدام مياه الصرف الصحى المعالجة \\
\hline V & $\cdot, 9 \vee$ & r,74 & استخدام مياه الصرف الصحي المعالجة قى الزراعة يعمل على فتح أسواق عمل جديدة \\
\hline 0 & $1,1 \mathrm{r}$ & $r, \vee \uparrow$ & هناك ضرورة للإنفاق على معالجة مياه الصرف الصحى \\
\hline 7 & $\cdot, \wedge 9$ & ґ,Ћ & الخشبية عن استخدائلادل مياه الصرف الصحى المعالجة في مجال زراعة الغابات \\
\hline 9 & 1,1 . & r,o. & الخشبية عن اسئد اجنتاعل مياه الصرف الصحى المعالجة في مجال زراعة الغابات \\
\hline$\varepsilon$ & $\cdot, \wedge 9$ & 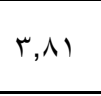 & الخشبية عن اسئد بيئي \\
\hline 1. & $1, \cdots$ & $\mathrm{r}, \mathrm{rV}$ & استخدام مياه الصرفت الصحي في زراعة الأثجار الخثبية يساهم في إرتفاع جودتها \\
\hline
\end{tabular}

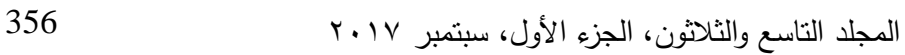




\section{يتضح من الجدول ما يلي:}

وافقت عينة البحث على أن" يستهلك القطاع الزراعي ما يقرب ـ ج\% من إجمالى المياه

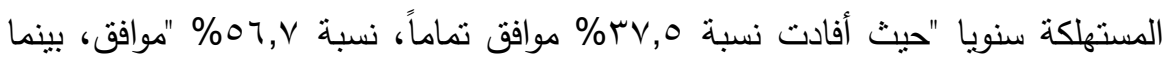

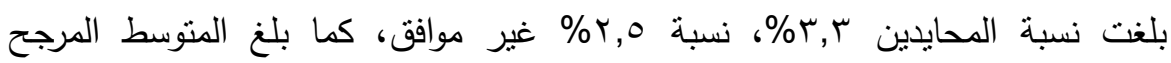
للإستجابات 9 r, ؛ بإنحراف معياري 70 ب, •. وكان " مياه الصرف الصحي المعالجة قد تزيد من الإنتاج لإحتوائها على بعض العناصر

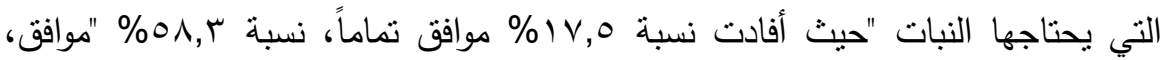

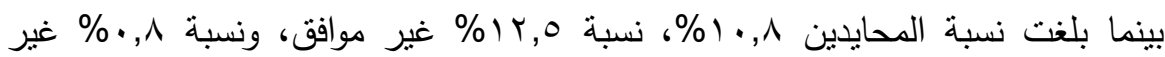

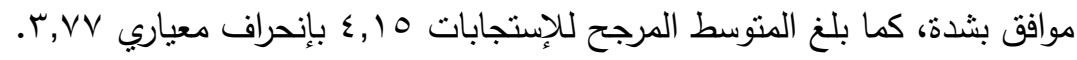

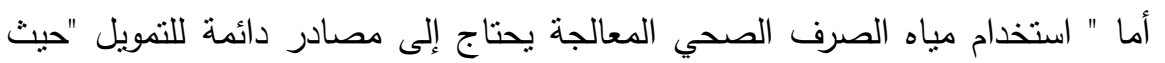

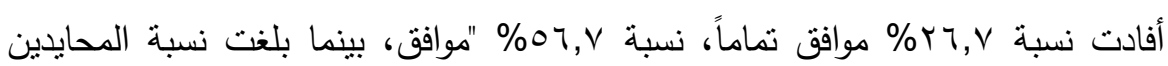

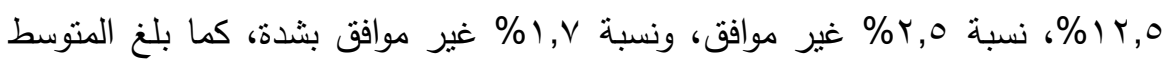
المرجح للإستجابات ع • , ,ـ بإنحراف معياري • م, • •.

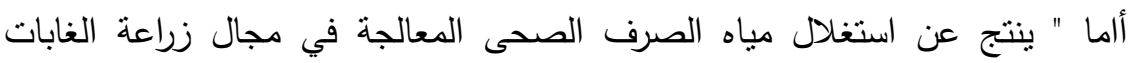

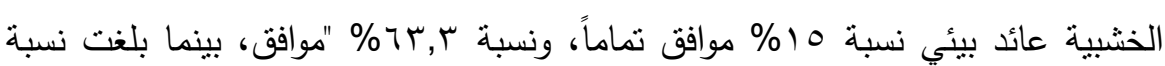

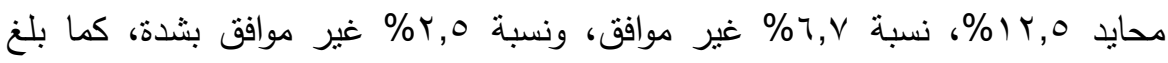

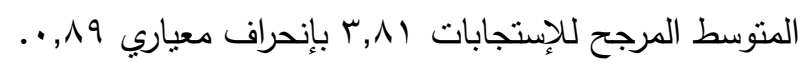

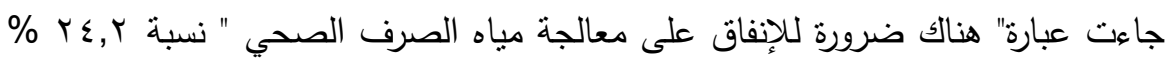

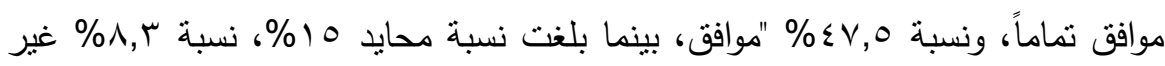

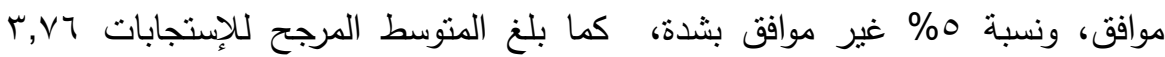
بإنحراف معياري r با, ا. • وجاء في المرتبة الأخيرة أن " نفقات معالجة مياه الصرف الصحي تشمل نفقات حماية

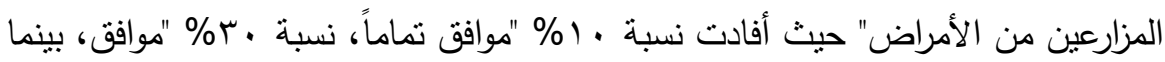




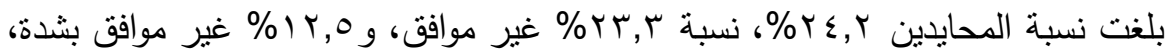

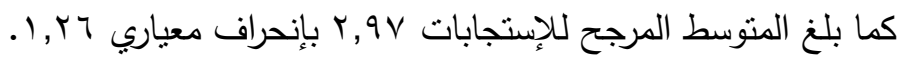

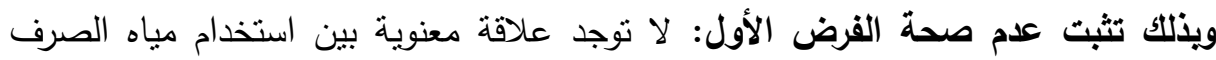

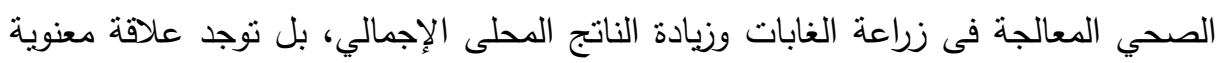

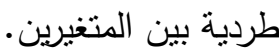
جدول رقم(ץ): التكرارات النسبية \% والإحصاء الوصفي للفرض الثانى

\begin{tabular}{|c|c|c|c|}
\hline 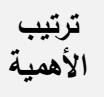 & إنحراف & 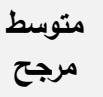 & أسئلة الدراسة \\
\hline 1 & $\cdot, 10$ & $\varepsilon, 17$ & التلوثذام مياه الصرف الصحي المعالجة بساعد فى حماية الييئة من \\
\hline 1. & $1, \mathrm{r \Lambda}$ & $r, \Sigma \varepsilon$ & مصادر المباه في مصر آمنة لا تحتاج إلى ترشيد \\
\hline 7 & $1,1 \leqslant$ & $r, 0 \varepsilon$ & تلعالجية مياه الصرف الصحي لتستخدم في زراعة النباتات والأشجار \\
\hline $\mathrm{v}$ & $1, \cdot r$ & $r, \xi$. & ميناجية الصنباتات الصحى المعالجة تعد غنية بالعناصر اللازمة لزيادة \\
\hline$r$ & $1, \cdot \varepsilon$ & $r, \wedge V$ & لا يسعة بتربية الماشية فى الحقول المروية بمياه الصرف الصحي \\
\hline ० & $1, \ldots$ & $r, \wedge$. & المزروعات مياه الصرف الصحى المعالجة تسبب نشر بعض الآفات في \\
\hline 9 & $1, r 4$ & r,V & الصوفى خدمات صحية في زعلاجية للمزارعين المستخدمين لمياه الصرف \\
\hline$\wedge$ & $1, r$ & $r, \wedge 9$ & الصتح وسائل الحماية من الأضرار الناتجة عن استخدام مياه الصرف \\
\hline r & $\cdot, \wedge T$ & $r, \wedge \Lambda$ & والحفاظ على صحة الإنسان الصحى يؤدى إلى التخلص من النفايات السائلة \\
\hline$\varepsilon$ & •,9 & $r, \Lambda r$ & 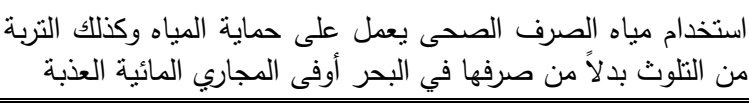 \\
\hline
\end{tabular}




\section{يتضح من الجدول ما يلي:}

وافقت عينة البحث على أن" استخدام مياه الصرف الصحي المعالجة بساعد فى حماية

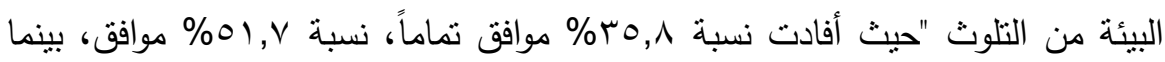

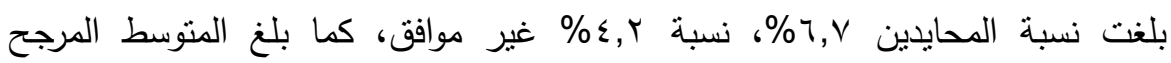

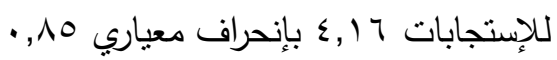

وكان " معالجة مياه الصرف الصحي يؤدى إلى التخلص من النفايات السائلة والحفاظ

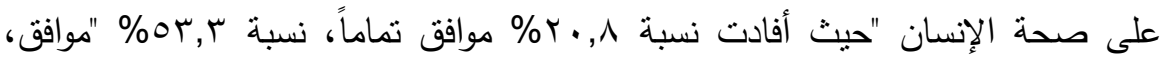

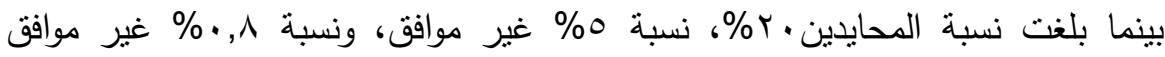

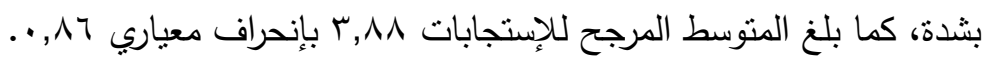

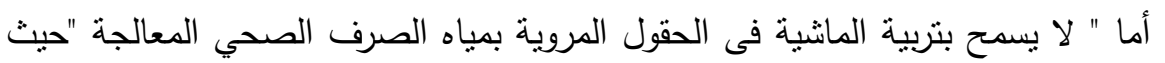

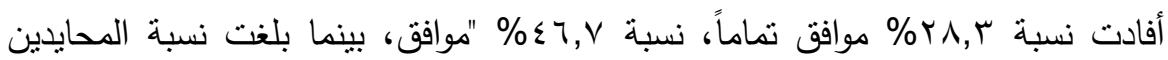

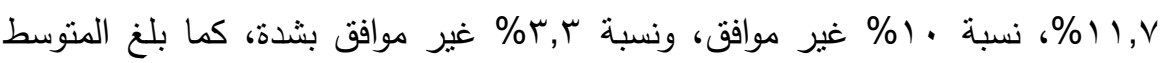

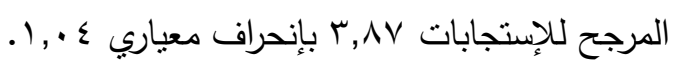
أما " استخدام مياه الصرف الصحي يعمل على حماية المياه وكذللك التربة من التلوث

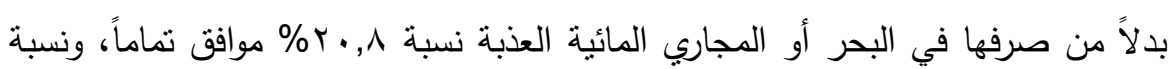

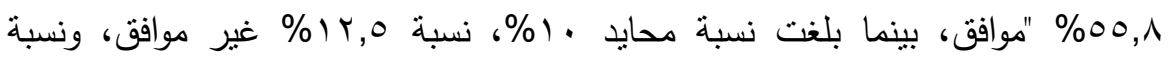

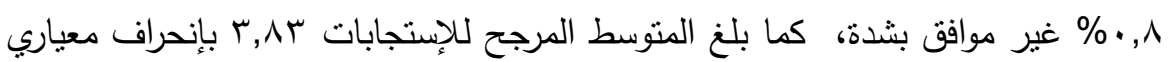
. .94

جاءت عبارة" استخدام مياه الصرف الصحي المعالجة تسبب نشر بعض الآفات في

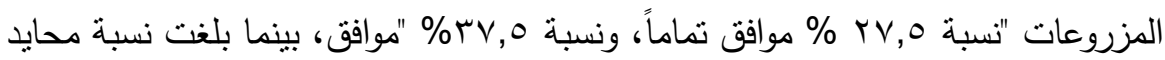

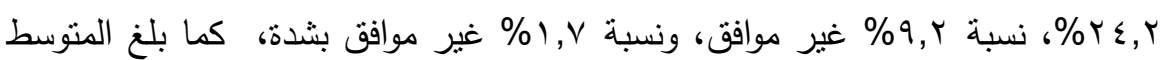

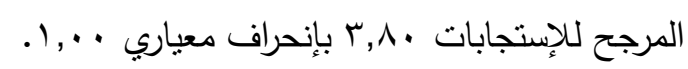

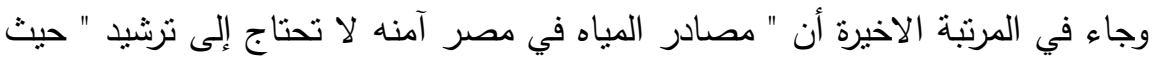

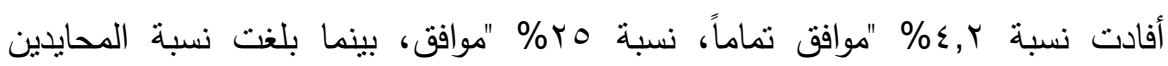

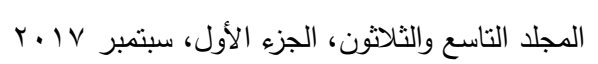




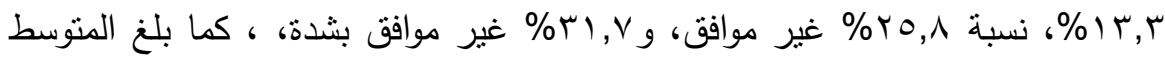

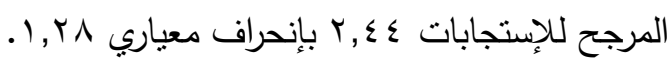

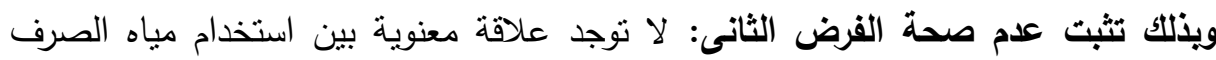

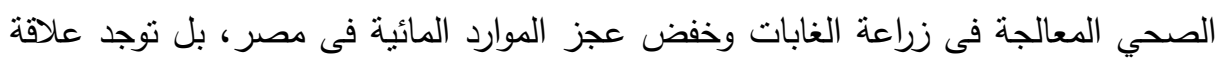
معنوية طردية بين المتغيرين. جدول رقم(ץ): التكرارات النسبية \% والإحصاء الوصفي للفرض الثالث

\begin{tabular}{|c|c|c|c|}
\hline الأهمبية & معياري & متوسط & 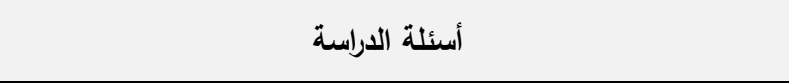 \\
\hline r & $\cdot, \wedge)$ & $\Gamma, 9 \wedge$ & ليتحملب مراعاة نسبة الملوحة في التربة ومياه الصرف الصحي المعالجة \\
\hline $\mathrm{V}$ & $1, \cdot \varepsilon$ & $r, \varepsilon r$ & مياه الصرف الصحى المعالجة تحمل نفس لون المياه العادية \\
\hline 1 & $\cdot, \wedge 9$ & r, 99 & يجب على المزارعين أخذ الإحتياطات الصحية عند استخدامهم لمياه \\
\hline 7 & $\cdot, 94$ & $r, \leqslant 0$ & ويمكن استخدام المياه الناتجة المعالجة الحيوية المنتهية بالترسيب والتطهير \\
\hline$r$ & $1, \cdot 1$ & $r, 94$ & ينفز المزارعين من استخدام مياه الصرف الصحي المعالجة في الري \\
\hline$\Lambda$ & $1,1 \mathrm{~V}$ & $r, 9 \leqslant$ & مباه الصرف الصحى المعالجة لا نتاسب المحاصيل التى تقوم بزراعتها \\
\hline 0 & $\cdot, \wedge \vee$ & ґ,૧ & 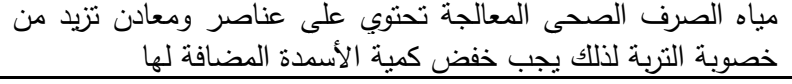 \\
\hline$\varepsilon$ & $\cdot, \vee \vee 9$ & $\Gamma, \wedge \wedge$ & لا يضب مراعاة الحمل الميكروبي في مياه الصرف الصحي المعالجة حتى \\
\hline
\end{tabular}

\section{يتضح من الجدول ما يلي:}

وافقت عينة البحث على أن" يجب على المزارعين أخذ الإحتياطات الصحية عند

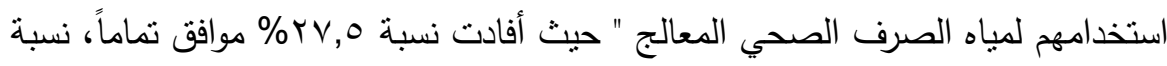

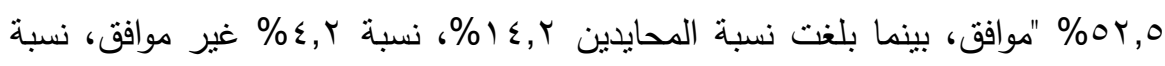

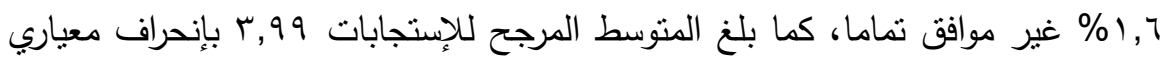
$\cdot, \wedge 9$

وكان "يجب مراعاة نسبة الملوحة في التربة ومياه الصرف الصحي المعالجة ليتحمها

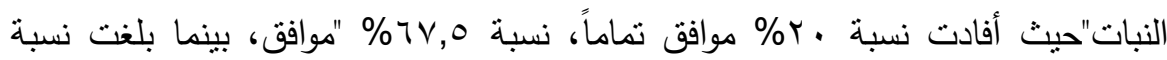




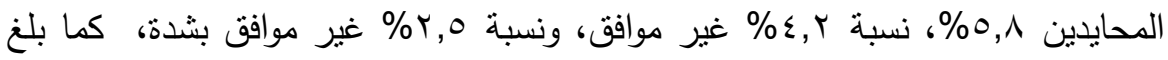

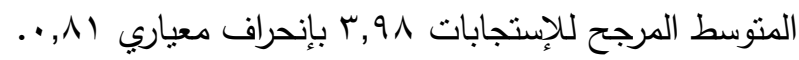
أما " ينفر المزارعين من استخدام مياه الصرف الصحي المعالجة في الري " أفادت نسبة بادية

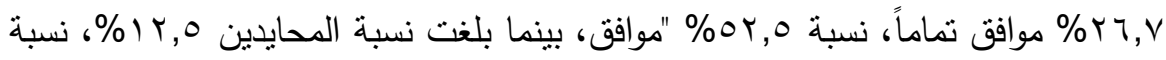

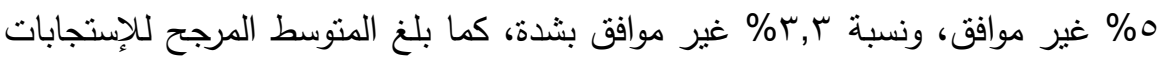

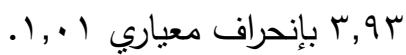
أما " يجب مراعاة الحمل الميكروبي في مياه الصرف الصدي الصي المعالجة حتى لا يضر

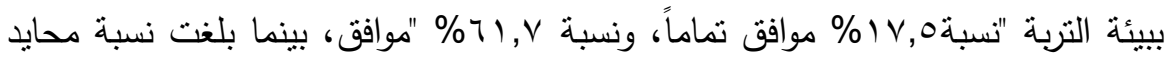

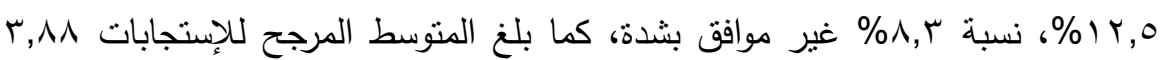

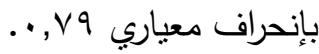
جاءت عبارة" مياه الصرف الصحي المعالجة تحتوي علي عناصر ومعادن تزيد من

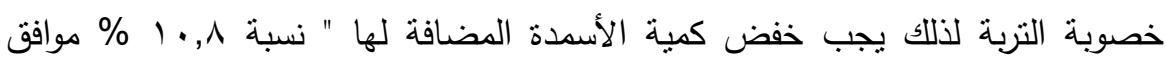

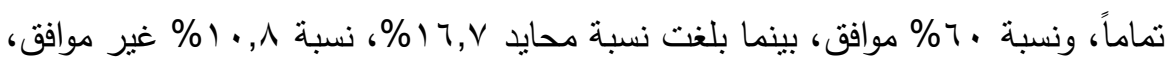

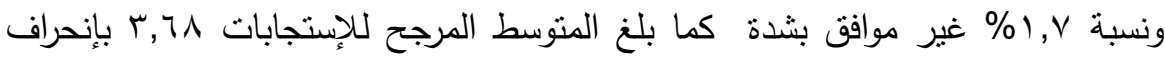

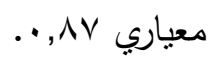

وجاء في المرتبة الاخيرة أن " مياه الصرف الصحي المعالجة لا تتاسب المحاصيل التي

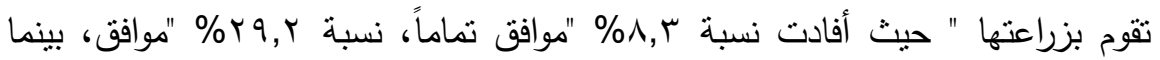

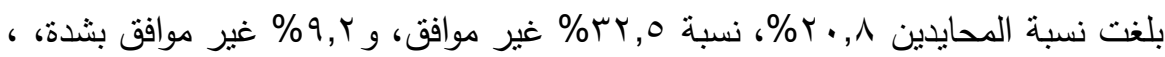

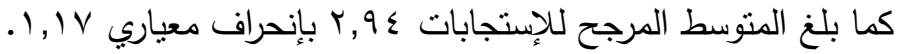
ويذلك تثبت صحة الفرض الثالث: نوجد علاقة معنوية طردية بين إستخدام مياه الصرف الصحي المعالجة وتقليل التلوث البيئى فى مصر . 


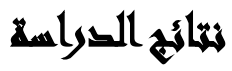

ا ـ فصل الملوثات الكيميائية من مياه الصرف الصحى فى المناطق الحضرية يسهل العلاج

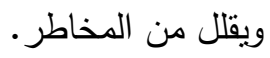

r. تعزيز القدرات المؤسسية وإقامة روابط بين توصيل المياه والصرف الصحى من خلال

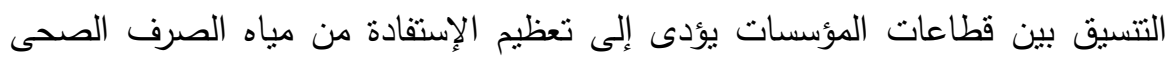

$$
\text { والحد من مخاطرها البيئية والصحية. }
$$

r. يصاحب التطوير والتتمية الزراعية للغابات خلق فرص عمل جديدة في هذه المناطق

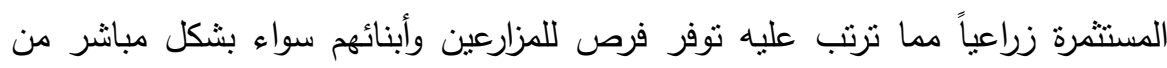

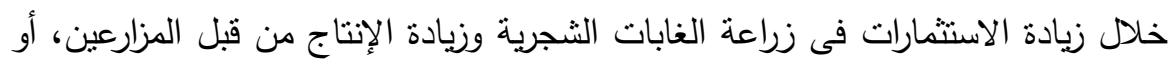
بشكل غير مباشر من خلال توفير فرص عمل إضافية في القطاعات الأخرى المساندة

$$
\text { للحكومية منها والأهلية. }
$$

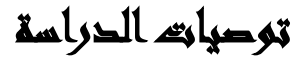

ا ـ تشجيع الاستثمار فى مجال الغابات الثجرية وعرض النماذج المقترحة على المستثرين. r. يمكن تحسين إدارة مياه الصرف الصحى من خلال تحسن السياسات والحوارات المؤسسية

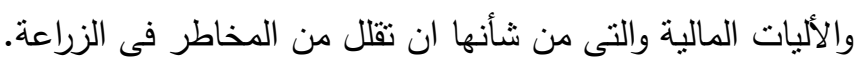

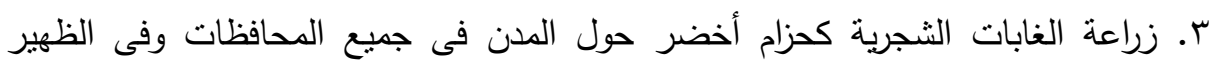

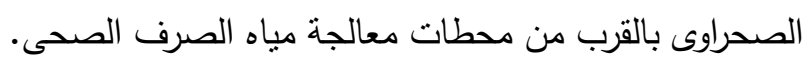

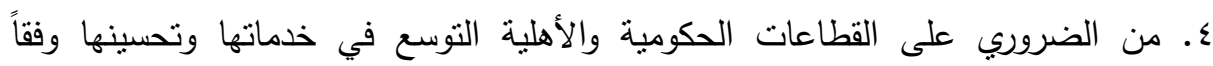
لمتطلبات التتمية المنكاملة لمناطق الغابات والتي لا تقتصر على تتمية القطاع الزراعي فى الغابات فقط بل تشمل جميع القطاعات الأخرى ذات العلاقة بحياة السكان في هذه المناطق. 


\section{المرآئar}

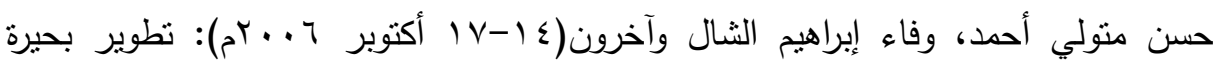

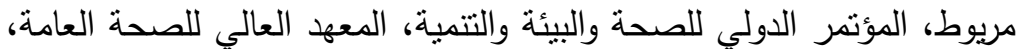

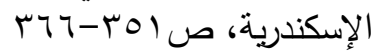

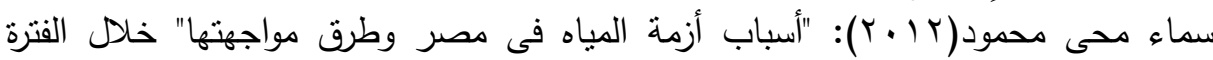

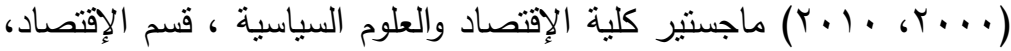

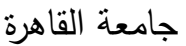

عماد رجب رسلان(r ( • r): أزمات المياه والخيارات الإستراتيجية، مؤتمر إدارة أزمات المياه

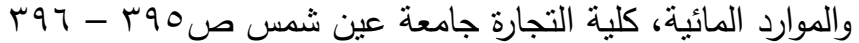

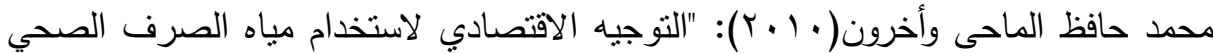

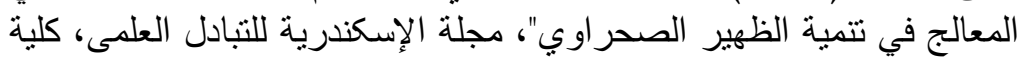

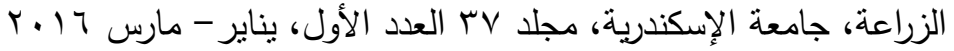

محدد كامل عبد العزيز : الصحة والبيئة - التلوث البيئي وخطره الدائم على صحتنا، الهيئة البئة

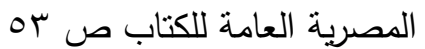

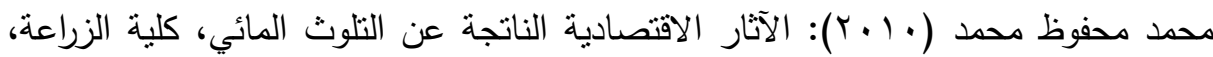

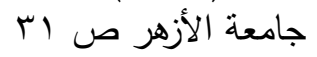

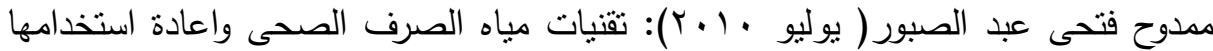

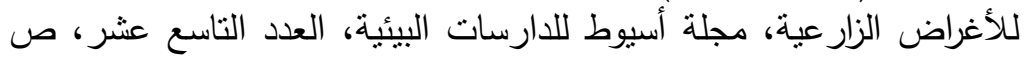

ए乏

نبيل فتحى السيد قنديل(T ( ب): تعظيم الإستفادة من مياه الصرف الصحي المعالج فى الصى

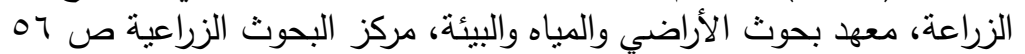

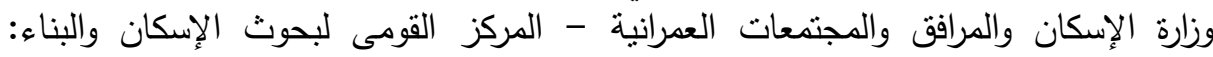

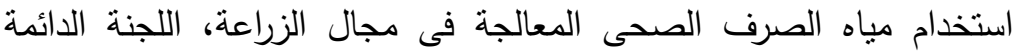

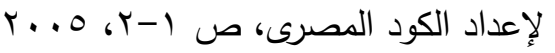

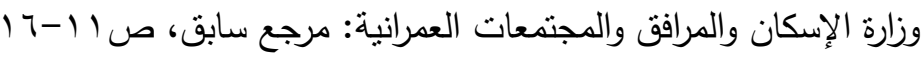

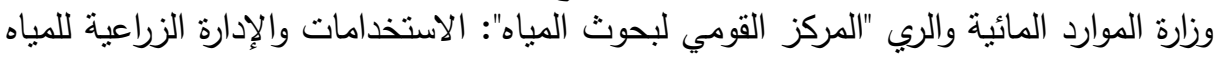

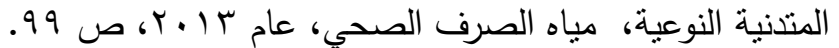

Ali Shehata Osman, Slaah-Eldeen Mohamed Ewais, Alsaid Ahmed Abd-Elatif: Risk assessment of waste water irrigation on the agricultural land, Egyptian Journal of Applied Sciences, vol.18, issue.8, p.342-353, 2013.

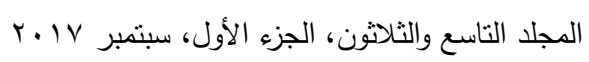


Hany A. E. El Gerum:The use of some aquatic plants to improve the effluents of an aerated lagoon system.). Journal of Environmental Sciences, Institute of Environmental Studies and Research, Ain Shams University, Egypt 2011.

\title{
AN ECONOMIC STUDY ON THE USE OF TREATED WASTEWATER IN FOREST FARMING - AN APPLIED STUDY ON SARABIUM FOREST, ISMAILIA GOVERNORATE
}

\author{
Mandour, A. F. ${ }^{(1)}$; Abd Elgany, N. A. ${ }^{(2)}$; Hewahy, M. A. ${ }^{(3)}$ \\ and Mahmoud, Dalia, $S_{.}^{(4)}$
}

1) Faculty of Commerce, Ain Shams University 2) Vice President of Ain Shams University for Community and Environment Affair 3) Institute of Studies and Environmental Research, Ain Shams University 4) General Administration of Scientific Research, Ain Shams University

\begin{abstract}
The study aims to study a proposed economic study for the use of treated wastewater cultivation of wood forests and to benefit from their production in many industries. The treatment of wastewater and its use for irrigation is an important option for the water source, The nutrients needed by plants are fertilizer, and the re-use of treated wastewater is one of the most widely used water-use methods due to the decline in fresh water.

The use of non-traditional water resources is one of the main tasks of all those interested in development in Egypt, through the expansion of agriculture in the Sahara Desert for the production of timber to
\end{abstract}

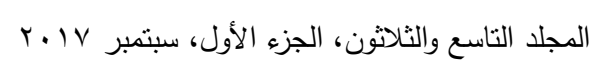


increase the burden on the import bill and add new land outside the valley and delta without using traditional water sources for irrigation.

The researchers followed the descriptive method in the analysis by means of data, information and statistics related to the subject of the study. The sample items were distributed according to gender (males,females), Educationallevel (university qualification above, intermediate qualification, intermediate and lower qualification, illiteracy),age group and administrative level (higher, middle, executive), And the number of (150) single. The statistical method was used to select the measuring tools and verify the validity of the hypotheses using the appropriate statistical methods and to derive the results by interpreting them.

\section{The main Results of this study are:}

1. Utilization of treated water in the field of woodland forestry produces economic, social and environmental benefits that contribute to the sustainable development of marginal and untapped desert areas.

2. Wastewater management can be improved through improved institutional policies and financial mechanisms.

\section{The main recommendations of the study:}

1. Encouraging investment in the cultivation of woodland forests and presenting the proposed models to investors.

2. The need to expand the establishment of purification plants and treatment of wastewater for reuse as a non-conventional source of water in accordance with their quality and so as not to cause any health or environmental damage so as not to be affected by human health and then its productivity.

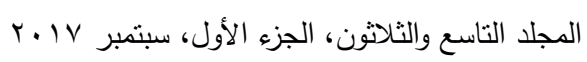

